\title{
Insights from Operando and Identical Location (IL) Techniques on the Activation of Electrocatalysts for the Conversion of $\mathrm{CO}_{2}$ : A Mini-Review
}

\begin{abstract}
Abhijit Dutta*a, Kiran Kiranª, Motiar Rahaman", Ivan Zelocualtecatl Montiela, Pavel Moreno-Garcíaa, Soma Vesztergomª, ${ }^{\mathrm{a}}$, Jakub Drnec ${ }^{\mathrm{c}}$, Mehtap Oezaslan ${ }^{\mathrm{d}}$, and Peter Broekmann ${ }^{{ }_{\mathrm{a}}}$
\end{abstract}

\begin{abstract}
In this mini-review we compare two prototypical metal foam electrocatalysts applied to the transformation of $\mathrm{CO}_{2}$ into value-added products (e.g. alcohols on $\mathrm{Cu}$ foams and formate on Bi foams). A substantial improvement in the catalyst performance is typically achieved through thermal annealing of the as-deposited foam materials, followed by the electro-reduction of the pre-formed oxidic precursors prior or during the actual $\mathrm{CO}_{2}$ electrolysis. Utilizing highly insightful and sensitive complementary operando analytical techniques (XAS, XRD, and Raman spectroscopy) we demonstrate that this catalyst pre-activation process is entirely accomplished in case of the oxidized Cu foams prior to the formation of hydrocarbons and alcohols from the $\mathrm{CO}_{2}$. The actually active catalyst is therefore the metallic $\mathrm{Cu}$ derived from the precursor by means of oxide electro-reduction. Conversely, in their oxidic form, the $\mathrm{Cu}$-based foam catalysts are inactive towards the $\mathrm{CO}_{2}$ reduction reaction (denoted ec- $\mathrm{CO}_{2} \mathrm{RR}$ ). Oxidized $\mathrm{Bi}$ foams can be regarded as an excellent counter example to the above-mentioned $\mathrm{Cu}$ case as both metallic and the thermally derived oxidic $\mathrm{Bi}$ foams are highly active towards $\mathrm{ec}-\mathrm{CO}_{2} \mathrm{RR}$ (formate production). Indeed, operando Raman spectroscopy reveals that $\mathrm{CO}_{2}$ electrolysis occurs upon its embedment into the oxidic $\mathrm{Bi}_{2} \mathrm{O}_{3}$ foam precursor, which itself undergoes partial transformation into an active sub-carbonate phase. The potential-dependent transition of sub-carbonates/oxides into the corresponding metallic $\mathrm{Bi}$ foam dictates the characteristic changes of the ec- $\mathrm{CO}_{2} \mathrm{RR}$ pathway. Identical location (IL) microscopic inspection of the catalyst materials, e.g. by means of scanning electron microscopy, demonstrates substantial morphological alterations on the $\mathrm{nm}$ length scale on the material surface as consequence of the sub-carbonate formation and the potential-driven oxide reduction into the metallic $\mathrm{Bi}$ foam. The foam morphology on a mesoscopic length scale (macroporosity) remains, by contrast, fully unaffected by these phase transitions.
\end{abstract}

Keywords: Catalyst activation $\cdot \mathrm{CO}_{2}$ reduction reaction · Identical location (IL) technique · Metal foam · Operando spectroscopy

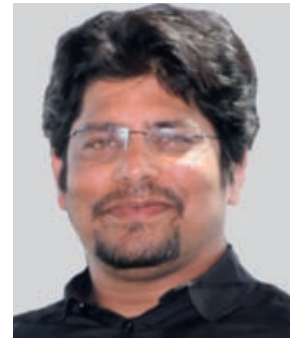

Dr. Abhijit Dutta obtained his $\mathrm{PhD}$ in chemistry from the Indian Institute of Engineering Science and Technology, Kolkata. During his $\mathrm{PhD}$ studies, his research mainly focused on the development of Pt and non-Pt based nanostructured materials for the application to fuel cells such as alcohol electro-oxidation, hydrogen oxidation, and the oxygen reduction reaction. He worked as a post-doctoral fellow at the National University of Singapore, Singapore. In 2015 he joined the interfacial electro-chemistry group of Prof. Peter Broekmann at the University of Bern, Switzerland, where he focuses on the development of various operando techniques (Raman, XAS, and $\mathrm{XRD}$ ) to characterize novel electrocatalysts for the selective conversion of $\mathrm{CO}_{2}$ into value-added products.

${ }^{*}$ Correspondence: Prof. Dr. P. Broekmanna ${ }^{2}$ E-mail: peter.broekmann@dcb.unibe.ch; Dr. A. Duttaa , E-mail: abhijit.dutta@dcb.unibe.ch

aUniversity of Bern, Department of Chemistry, Biochemistry and Pharmaceutical Sciences; ' ${ }^{\circ}$ ötvös Loránd University, Department of Physical Chemistry, H-1117 Budapest, Pázmány Péter sétány 1/A, Hungary; 'European Synchrotron Radiation Facility, Grenoble, France; Institute of Technical Chemistry, Technical University of Braunschweig, Braunschweig, Germany; \#Current address: Department of Chemistry, University of Cambridge, Cambridge, United Kingdom

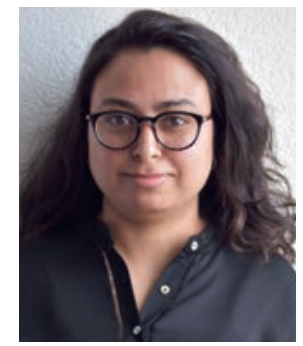

Kiran Kiran received her MSc in physics from Maharshi Dayanand University (M.D.U.) India in 2015. She is currently pursuing her $\mathrm{PhD}$ at the Department of Chemistry, Biochemistry and Pharmaceutical Sciences at the University of Bern under the supervision of Prof. Peter Broekmann. Her research interests are focused on the synthesis of novel electrocatalysts for $\mathrm{CO}_{2} \mathrm{RR}$ applications.

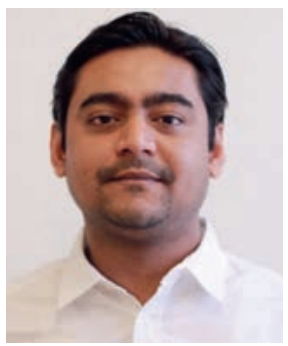

Dr. Motiar Rahaman received his MSc in chemistry (2013) from the Indian Institute of Technology Madras, India. He obtained his $\mathrm{PhD}$ (2018) from the University of Bern (group of Peter Broekmann) on the topic of electrochemical conversion of $\mathrm{CO}_{2}$ into value-added products. Currently he works as a post-doctoral fellow at the University of Cambridge (UK). 


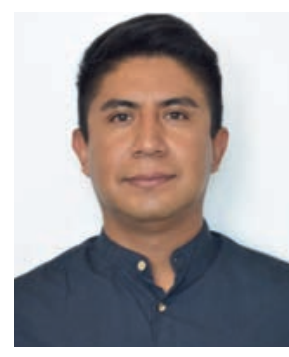

Ivan Zelocualtecatl Montiel received his BSc and MSc in chemistry from the Meritorious Autonomous University of Puebla (BUAP) in 2013 and 2016, respectively. He is currently a $\mathrm{PhD}$ candidate at the Department of Chemistry, Biochemistry and Pharmaceutical Sciences at the University of Bern under the supervision of Prof. Dr. Peter Broekmann. His research interest is focused on the development of novel catalysts for the electroreduction of $\mathrm{CO}_{2}$.

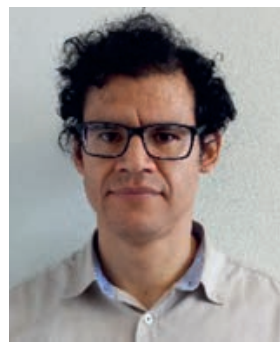

Dr. Pavel Moreno-García received his $\mathrm{PhD}$ in chemistry and molecular science from the University of Bern in 2013, under the supervision of Prof. Dr. Thomas Wandlowski. At that time, his work was devoted to the study of electron transport through nano-objects at electrified interfaces by in situ STM. In 2013, he joined the group of Prof. Dr. Peter Broekmann, where he is involved in research activities on electrocatalysis, metal corrosion and laser ablation mass spectrometry.

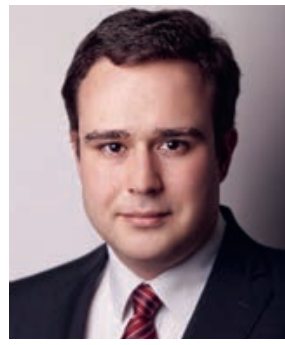

Dr. Soma Vesztergom obtained his MSc (2010) and $\mathrm{PhD}$ (2014) degrees in chemistry, working with Prof. Dr. G. G. Láng at Eötvös Loránd University, Hungary. He was a post-doctoral researcher in Prof. Dr. Peter Broekmann's group at the University of Bern for one year (2014) and is a regular collaborator of this group since then. His research primarily focuses on instrumental developments in electrochemistry and on the modelling of electrocatalytic processes. Currently, he is an assistant professor at Eötvös Loránd University in Budapest.

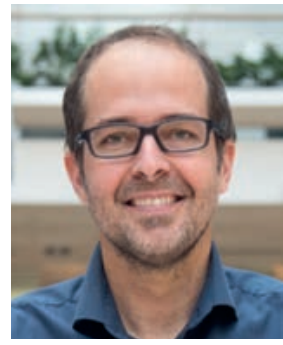

Dr. Jakub Drnec obtained his $\mathrm{PhD}$ degree at University of Victoria, Canada, in the field of surface electrochemistry. He is currently beamline scientist at the European Synchrotron (ESRF) in Grenoble (France), developing new high energy X-rays experimental techniques to study materials for energy conversion and storage. His main goal is to probe materials in their working environment in order to better understand their functioning. His current projects involve operando investigations of fuel cells and batteries, fundamental studies of electrocatalyst's degradation and structure-activity relationships, and development of operando electrochemical cells and data analysis routines.

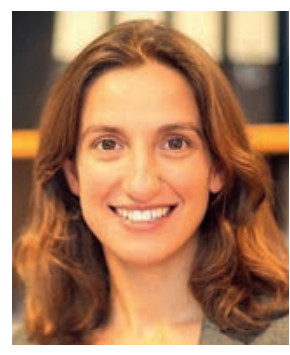

Prof. Dr. Mehtap Oezaslan obtained her $\mathrm{PhD}$ degree (2012) in electrochemistry from Technische Universität Berlin, Germany. After a post-doctoral stay at the Electrochemistry Laboratory Group, Paul Scherrer Institute, Switzerland, she was a Junior professor for Electrochemistry at Carl von Ossietzky University of Oldenburg from 2014-2019. Since June 2019, she holds a Full (W3) Professorship at the Institute of Technical Chemistry, Technische Universität Braunschweig. Her research is focused on the development and characterization of electrocatalysts for PEM fuel cells and electrolysis.

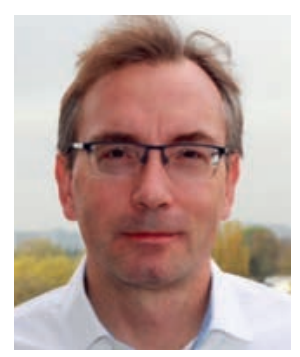

Prof. Dr. Peter Broekmann obtained his MSc in chemistry (1998) and a PhD (2000) from the University of Bonn. After a postdoctoral stay at the University of Twente (The Netherlands) in 2001, he became project leader at the Institute of Physical Chemistry in Bonn. Since 2008 he holds a lecturer position for electrochemistry at the University of Bern. His research focuses on metal deposition processes for semiconductor and electrocatalysis applications.

\section{Introduction}

The conversion of $\mathrm{CO}_{2}$ into value-added products by means of electrolysis (denoted hereafter ec- $\mathrm{CO}_{2} \mathrm{RR}$ ) is considered a promising approach to mitigate the negative impact that $\mathrm{CO}_{2}$ is exerting on the global climate. ${ }^{[1]}$ The vision of converting this environmentally harmful molecule into chemical platform chemicals or synthetic fuels on large industrial scale even offers the unique chance of decreasing the existing atmospheric $\mathrm{CO}_{2}$ concentration, which already exceeds a level of $400 \mathrm{ppm}$. For this purpose, the ec- $\mathrm{CO}_{2} \mathrm{RR}$ has to be coupled in the future to advanced direct air capture technologies. ${ }^{[2-4]}$ The products of $\mathrm{CO}_{2}$ reduction - typically light-weight molecules such as carbon monoxide, formic acid or alcohols - could be used as either chemical feedstock and transformed further into products of higher value, e.g. via Fischer-Tropsch synthesis or biotechnological transformations, ${ }^{[5]}$ or directly as 'green' fuels. The latter is considered vital for the so-called 'energy transition'. ${ }^{[6,7]}$ In particular, if a surplus of renewable energies, originating from solar, wind, or hydroenergy sources, is used to operate the highly endergonic and energy demanding ec- $\mathrm{CO}_{2} \mathrm{RR}$, this conversion process might become truly sustainable and possibly a key element of a future circular economy. Without doubt, ec- $\mathrm{CO}_{2} \mathrm{RR}$ has the highest potential of contributing to the closing of the anthropogenic $\mathrm{CO}_{2}$ cycle (see Fig. 1). ${ }^{[8]}$

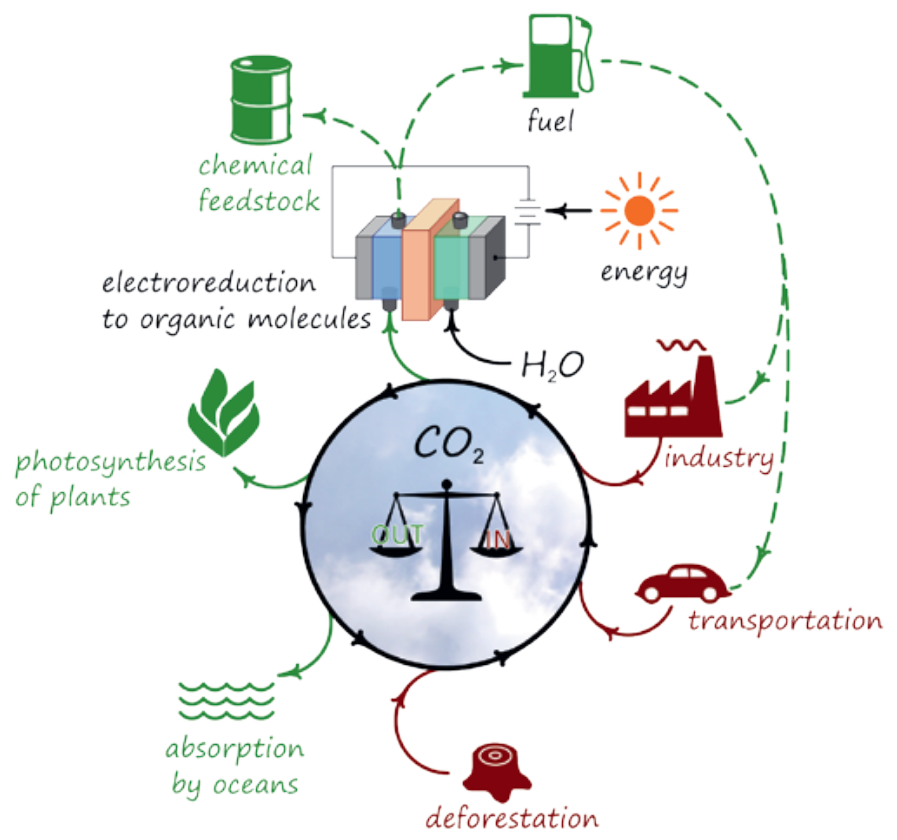

Fig. 1. Schematic depiction of the overall concept to close the anthropogenic carbon cycle by ec- $\mathrm{CO}_{2} \mathrm{RR}$ : Towards sustainable conversion of $\mathrm{CO}_{2}$ into synthetic fuels and chemical feedstock powered by solar energy. Adapted from ref. [8], with permission from John Wiley and Sons.

Most of the known electrochemical $\mathrm{CO}_{2}$ transformations are, however, still immature and uneconomic. ${ }^{[9]}$ One reason for this is related to electrocatalysts which still require substantial improve- 


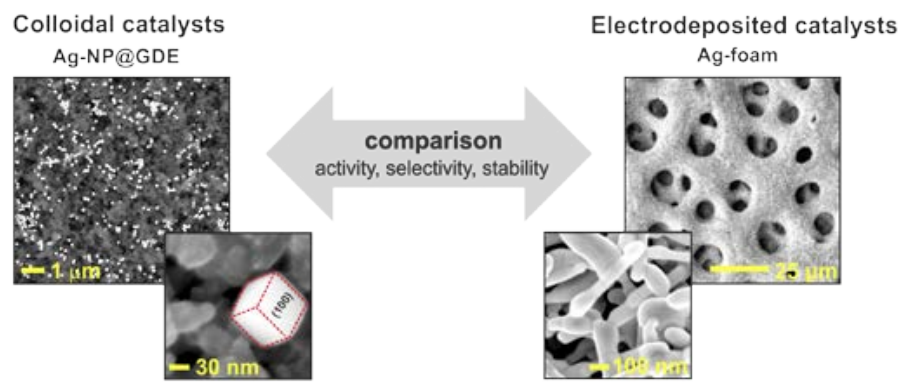

Fig. 2. Complementary catalyst concepts for the ec- $\mathrm{CO}_{2} \mathrm{RR}$ : carbonsupported colloidal nanoparticles (left) versus electrodeposited metal foams (right) exemplified for Ag-based electrocatalysts. Adapted from refs $[13,19]$, with permission of the American Chemical Society.

ments in terms of material costs, (energy) efficiency and catalyst reliability (stability). ${ }^{[8]}$ Additionally, electrocatalysts are essential not only to accelerate the intrinsically slow ec- $\mathrm{CO}_{2} \mathrm{RR}$ process but also to direct the electrolysis reaction towards the desired reaction products (selectivity). ${ }^{[10]}$ It is, however, not only the chemical nature of the catalyst itself which governs the resulting ec- $\mathrm{CO}_{2} \mathrm{RR}$ product distribution ${ }^{[10]}$ but also its morphological characteristics on various length scales. ${ }^{[11]}$ Some of the most common ec-CO $\mathrm{RR}$ catalyst concepts rely on the use of nanoparticulate materials. ${ }^{[12]} \mathrm{A}$ clear advantage of this classical approach of catalyst design is that the whole spectrum of (mature) colloid chemistry can be applied to synthesize nano-materials of various shapes, morphologies and size distributions. In addition, this approach offers a straightforward and well-established route to functionalize highly porous carbon supports (e.g. gas diffusion electrodes (GDEs), Fig. 2) that are used in gas-fed electrolyzer systems that can reach ec- $\mathrm{CO}_{2} \mathrm{RR}$ current densities of technological relevance $\left(>200 \mathrm{~mA} \times \mathrm{cm}^{-2}\right)$. $[13,14]$

A relatively new and alternative concept of ec- $\mathrm{CO}_{2} \mathrm{RR}$ catalyst design relies on the electrodeposition of foam-type materials ${ }^{[11,15-17]}$ (Fig. 2), which, similar to their nanoparticulate counterparts, offer a large surface area that is not only accessible to reactants but also enables fast, multidimensional electron transport. ${ }^{[17]}$ Moreover, self-standing foams can directly be employed as cathodes for the ec- $\mathrm{CO}_{2} \mathrm{RR}$ often without the need for additional mechanical support, rendering the application of conductive binders unnecessary. ${ }^{[17]}$

Herein we review and compare the structural, compositional and performance characteristics of two prototypical foam electrocatalysts that are based on $\mathrm{Cu}$ and $\mathrm{Bi}$ systems published recently. ${ }^{[11,18-20]}$ Among various materials studied so far, $\mathrm{Cu}$ stands out as the only known mono-metallic catalyst that can produce multiple hydrocarbons and alcohols of various chain lengths at elevated rates from the ec- $\mathrm{CO}_{2} \mathrm{RR} \cdot{ }^{[10,21-26]}$ In this context, $\mathrm{C}-\mathrm{C}$ coupled (liquid) alcohols are of particular interest due to their high volumetric energy density (e.g. n-propanol: $\left.27.0 \mathrm{MJ} \mathrm{L}^{-1}\right)$. $^{[27]}$ Note that, prior to their use in operating electrolyzers, numerous as-synthesized/as-deposited ec- $\mathrm{CO}_{2} \mathrm{RR}$ catalysts require further activation as an essential pre-requisite to attain a highly selective $\mathrm{CO}_{2}$ conversion into the targeted product(s). ${ }^{[28-33]}$ The terms 'as-synthesized' and 'as-deposited' refer to the stage of catalyst preparation right after the initial electrodeposition of the catalyst material and prior to its further activation. A common approach of such catalyst activation involves the partial or complete surface oxidation of the as-deposited metallic foams, e.g. by thermal annealing in air. ${ }^{[20,29,31]}$ An ultimate activation step of such formed oxidic catalyst precursors is often only achieved in situ under reductive conditions prior to or during the actual $\mathrm{CO}_{2}$ electrolysis. ${ }^{[19,31,34]}$ Such oxidation/electro-reduction treatments not only lead to the further increase of the electrochemically active surface area of the catalyst but also often create those active sites on the foam surface which are required for highly selective ec- $\mathrm{CO}_{2}$ RR. ${ }^{[28]}$ It should be emphasized that, at least in the case of copper-based materials, the oxidic precursors $\left(\mathrm{Cu}_{2} \mathrm{O}\right.$ or $\left.\mathrm{CuO}\right)$ formed upon thermal annealing are thermodynamically instable at electrolysis potentials typically applied during ec- $\mathrm{CO}_{2} \mathrm{RR},{ }^{[35]}$ which in turn results into the formation of so-called oxide-derived (OD) catalysts. ${ }^{[31,36]}$ In general, one possible complication of this catalyst activation approach lies in the reduced electric conductivity of the formed 'bulk' oxides. This can, in principle, lead to a 'kinetic' stabilization of the formed oxidic catalyst precursor phases even under the extremely cathodic potentials applied. In some rare cases one might therefore observe oxidic catalyst species even at potentials far beyond the stability regime predicted by thermodynamics. The specific role of oxides for the ec-CO $\mathrm{CO}_{2} \mathrm{R}$ mechanism and in particular the occurrence of oxygen species embedded inside the hosting metallic $\mathrm{Cu}$ matrix under reductive conditions are still the subject of highly controversial debates. To date, there is no ultimate consensus achieved in the literature on the potential-dependent stability of surface and sub-surface oxide/oxygen species and their specific role for the ec-CO RR. ${ }^{[19,20,33,37-42]}$ To address these mechanistic questions of catalyst activation, a highly complementary approach utilizing several operando techniques is needed, which provides various means of deriving structural and chemical information of the catalyst state under reactive conditions. ${ }^{[28]}$ When further combined with high-resolution imaging techniques, e.g. identicallocation electron microscopy (e.g. IL-SEM[28] or IL-TEM[43]), this holistic approach even permits discriminating transient phenomena of catalyst precursor reduction (activation). Fig. 3 depicts the set of complementary operando analytical techniques described herein. ${ }^{[19]}$

X-ray absorption spectroscopy (XAS) ${ }^{[19]}$ provides information on (i) the oxidation state (XANES: X-ray Absorption Near

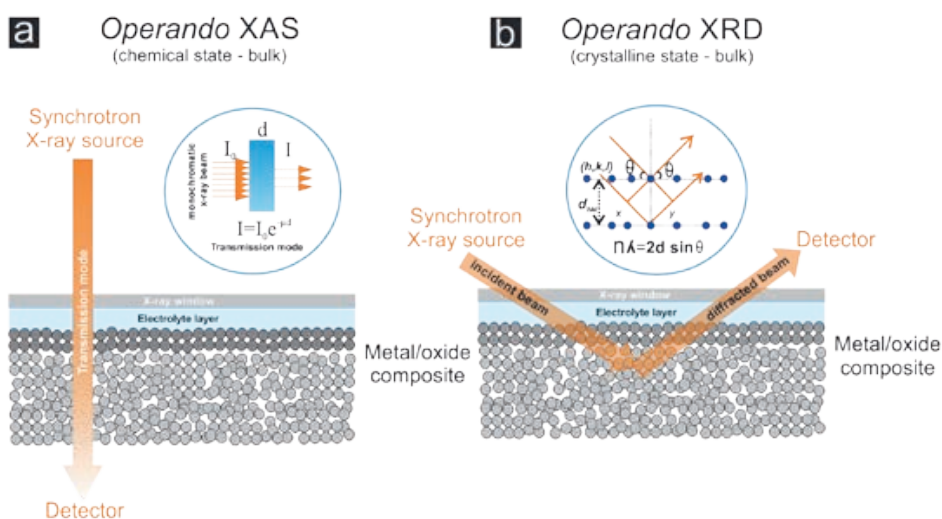

C Operando Raman (chemical state - surface)

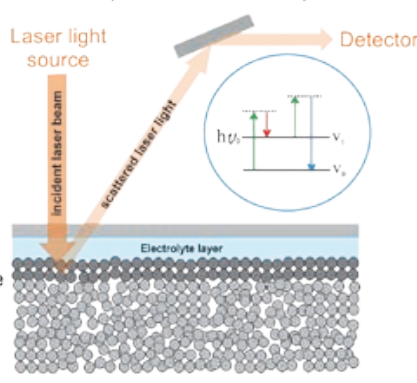

Fig. 3. Complementary operando analytical approaches to study the potential-dependent oxide precursor-metal conversion. a) Operando X-ray absorption spectroscopy (XAS); b) Operando X-ray diffraction $(\mathrm{XRD})$; c) Operando Raman spectroscopy. Adapted from ref. [19], with permission of Elsevier. 


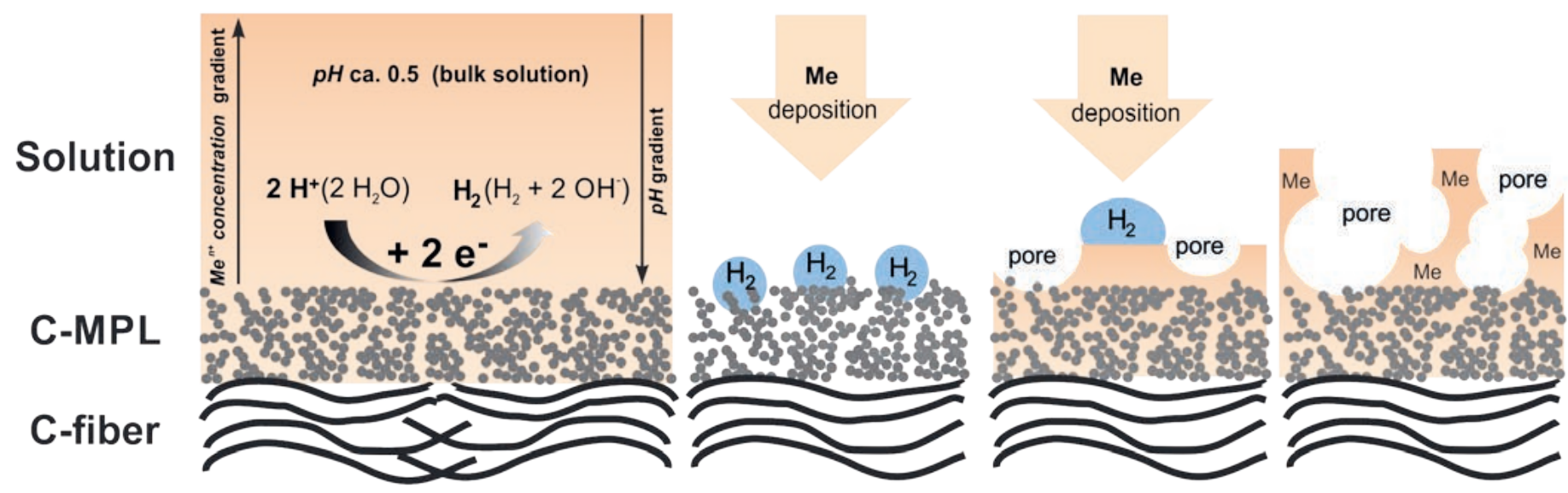

Fig. 4. Metal foam electrodeposition ('Me' deposition) by means of the dynamic hydrogen bubble template (DHBT) approach. The working principle is exemplified for a porous carbon support that finds use as gas-diffusion electrode (GDE). 'MPL' and 'Me' stand for microporous layer and metal, respectively. Adapted from ref. [18], with permission of the American Chemical Society.

Edge Structure) and (ii) the coordination number changes (EXAFS: Extended X-ray Absorption Fine Structure) that typically go along with the electro-reduction of the oxidic precursor materials. Compared to their nanoparticulate counterparts, metal foam electrocatalysts and their oxidic precursors exhibit a more unfavorable surface to volume (bulk) ratio (see e.g. Fig. 2). Therefore, information derived from XANES and EXAFS techniques originate predominantly from the 'bulk' of the foam material and comprise only marginal contributions from the respective catalyst surfaces. However, what makes the operando grazing-incidence X-ray absorption spectroscopy particularly valuable is its capability to probe these potential-dependent oxidation state transitions even when amorphous phases, lacking any long-range translational order, are involved. Note that the activation of $\mathrm{Cu}$ foam catalysts via thermal annealing and subsequent electroreduction often proceeds via amorphous $\mathrm{Cu}_{\mathrm{x}} \mathrm{O}$ phases. ${ }^{[19,20]}$

The operando X-ray diffraction (XRD) technique ${ }^{[19]}$ is highly complementary to XAS as it permits probing changes in the crystal structure of the foam catalysts, which typically accompany the potential-driven oxidation state changes.

Raman spectroscopy ${ }^{[19]}$ can be considered as the most surface sensitive operando technique among those employed herein. A particular strength of the operando Raman spectroscopy is that not only the potential-induced alterations of the catalyst themselves can be probed but, in addition, also the emergence of ec- $\mathrm{CO}_{2} \mathrm{RR}$ intermediate species, which might be chemisorbed on the evolving 'active' metallic catalyst surface. ${ }^{[19,44]}$

Herein we introduce $\mathrm{Cu}$ foams and their oxidic precursors as prototypical model systems where the oxide-metal transition (catalyst activation) is completed prior to (or at the very onset of) the ec-CO RR. $^{[19,20,28]}$ The actual foam catalysts, being active towards alcohol and hydrocarbons, can therefore be considered as truly oxidederived (OD). [19]

As a counter-example to that, we also discuss oxidized Bi foam catalysts ${ }^{[18]}$ used for the highly selective production of formate. Our investigations reveal that both the oxidized as well as the corresponding metallic foams exhibit pronounced electrocatalytic activity towards the ec- $\mathrm{CO}_{2} \mathrm{RR}$. Finally, we hint at two ec- $\mathrm{CO}_{2} \mathrm{RR}$ pathways that are distinctly active on oxide-derived $\mathrm{Cu}$ and $\mathrm{Bi}_{2} \mathrm{O}_{3} / \mathrm{Bi}$ foam electrocatalysts. ${ }^{[18]}$

\section{Experimental ${ }^{[18,19]}$}

Experimental details on the $\mathrm{Cu}$ and $\mathrm{Bi}$ foam preparation and the performed operando/IL investigations have already been detailed elsewhere. ${ }^{[11,18,19]}$ We therefore restrict ourselves here to a brief description of the applied experimental approaches.

\subsection{Preparation of the $\mathrm{Cu} / \mathrm{Cu}_{x} \mathrm{O}$ and $\mathrm{Bi} \mathrm{Bi}_{2} \mathrm{O}_{3}$ Foam Catalysts ${ }^{[11,19]}$}

Metallic $\mathrm{Cu}$ foams were electrodeposited onto activated carbon foil substrates (0.25 mm thick, 99.8\%, Alfa Aesar, Germany) using the dynamic hydrogen bubble template (DHBT) ${ }^{[15,16]}$ approach (see Fig. 4). The carbon foil support was then immersed into a $\mathrm{Cu}$ plating bath containing $0.2 \mathrm{M} \mathrm{CuSO}_{4} \cdot 5 \mathrm{H}_{2} \mathrm{O}$ and $1.5 \mathrm{M}$ $\mathrm{H}_{2} \mathrm{SO}_{4}$. For the galvanostatic deposition process, a current density of $j=-3.0 \mathrm{~A} \times \mathrm{cm}^{-2}$ (normalized to the geometric surface area of the carbon support) was applied for the duration of 5 seconds. The electrodeposited $\mathrm{Cu}$ foams were further subjected to thermal annealing in air for $12 \mathrm{~h}$ at a temperature of $300^{\circ} \mathrm{C}$ using a tube furnace (GERO, GmbH, Germany).

For the operando Raman spectroscopy studies, metallic $\mathrm{Bi}$ foams were electrodeposited on graphitic carbon foils (Alfa Aesar) that were activated prior to the Bi deposition by annealing in air at $550{ }^{\circ} \mathrm{C}$ for $12 \mathrm{~h}$ in a tube furnace. To further increase the electrochemically active surface area Bi foams were deposited on highly porous carbon fiber cloths (gas diffusion electrodes, GDEs, Fuel Cell, USA) for the electrolysis experiments. The carbon fiber cloths were used as received. The standard plating bath for the $\mathrm{Bi}$ foam deposition was composed of $1.5 \mathrm{M} \mathrm{H}_{2} \mathrm{SO}_{4}$ (prepared from $96 \% \mathrm{H}_{2} \mathrm{SO}_{4}$, ACS grade, Sigma-Aldrich) serving as the supporting electrolyte and $20 \mathrm{mM}$ bismuth ammonium citrate $\left(\mathrm{C}_{12} \mathrm{H}_{22} \mathrm{BiN}_{3} \mathrm{O}_{14}\right.$, purity $\geq 99.5 \%$ Sigma Aldrich). The galvanostatic $\mathrm{Bi}$ foam deposition was carried by applying a current density of $\mathrm{j}=-3.0 \mathrm{~A} \times \mathrm{cm}^{-2}$ (referred to the geometric surface area of the support electrode) for $20 \mathrm{~s}$. The as-prepared Bi foams were further subjected to thermal annealing in air at $300{ }^{\circ} \mathrm{C}$ for $12 \mathrm{~h}$, thus transforming the metallic $\mathrm{Bi}$ into fully oxidized $\mathrm{Bi}_{2} \mathrm{O}_{3}$.

\subsection{Operando X-ray Absorption Spectroscopy[19]}

XAS experiments were carried out at the SuperXAS (X10DA) beamline at the Swiss Light Source (SLS) in Villigen, Switzerland. The storage ring was operated at $2.4 \mathrm{GeV}$ and $400 \mathrm{~mA}$. For the operando spectroscopic experiments a dedicated liquid flow-cell was used. ${ }^{[45]} \mathrm{XAS}$ experiments were carried out in $\mathrm{CO}_{2}$-sat. 0.5 $\mathrm{M} \mathrm{KHCO}_{3}$ electrolyte solution $(\mathrm{pH}=7.2)$ in the potential range from $+0.8^{3} \mathrm{~V}$ to $-0.9 \mathrm{~V}$ vs. RHE. All potentials were iR-corrected.

\subsection{Operando X-ray Diffraction ${ }^{[19]}$}

Operando XRD experiments were performed at the high energy beamline ID31 of the European Synchrotron Radiation Facility (ESRF). The X-ray beam was mono-chromatized with a Laue-Laue monochromator to the energy of $69 \mathrm{keV}$ and focused to the size of $5 \times 20 \mu \mathrm{m}^{2}$ (vertical $\times$ horizontal) at the sample posi- 
tion. The 2D XRD patterns were collected with a Dectris Pilatus $2 \mathrm{M}$ CdTe detector. A custom-made PEEK electrochemical flow cell was used for the experiments. ${ }^{[46]}$ The measurements were performed in grazing incidence geometry (the incidence angle was less than 1 degree), in $\mathrm{CO}_{2}$-sat. $0.5 \mathrm{M} \mathrm{KHCO}_{3}$ electrolyte. A continuous flow of fresh $\mathrm{CO}_{2}$-sat. electrolyte solution through the spectro-electrochemical cell prevented any undesired accumulation of soluble $\mathrm{Cu}$ species in the investigated X-ray window. All potentials were iR-corrected.

\subsection{Operando Raman Spectroscopy ${ }^{[19]}$}

Raman spectra were recorded using a LabRAM HR800 confocal microscope (Horiba Jobin Yvon) at a working distance of 8 $\mathrm{mm}$ between the objective lens (LMPLFLN from Olympus, 50X magnification) and the sample with a numerical aperture of 0.1 in order to focus a diode-pumped solid-state or He-NE laser beam (excitation wavelength of 532 or $633 \mathrm{~nm}$, power of $3 \mathrm{~mW}$ ) on the sample. The Raman signal was collected in a back-scattering geometry using a lab-made spectro-electrochemical cell made of Kel-F. ${ }^{[47,48]} \mathrm{CO}_{2}$-sat. $0.5 \mathrm{M} \mathrm{KHCO}_{3}$ solution was used as the electrolyte. The ohmic drop was determined using the positive feedback technique and compensated during the measurement.

\subsection{Identical Location Scanning Electron Microscopy (IL-SEM)}

For the high-resolution (HR) identical location (IL) SEM imaging a Zeiss DSM 982 instrument was used.

\subsection{Product Analysis of the ec-CO $R_{2} R^{[11,18]}$}

All electrolysis experiments were carried out in $\mathrm{CO}_{2}$-sat. $0.5 \mathrm{M} \mathrm{KHCO}_{3}$ solution using a custom-built, air-tight glass-cell
(H-type) described elsewhere.[11] During electrolysis $\mathrm{CO}_{2}$ was continuously purged through the catholyte at a flow rate of 13 $\mathrm{mL} \times \mathrm{min}^{-1}$. The headspace of the electrolysis cell was directly connected to the gas sampling loop of the gas chromatograph (GC $8610 \mathrm{C}$, SRI Instruments). The GC was equipped with a packed Hayesep D column and a packed Molesieve 5A column. Argon (99.9999 \%, Carbagas) was used as the carrier gas. A flame ionization detector (FID) coupled to a methanizer was used to quantify $\mathrm{CO}$ and volatile hydrocarbons. A thermal conductivity detector (TCD) was used for the $\mathrm{H}_{2}$ detection. Non-volatile products (e.g. alcohols) were quantified by a second FID detector. After the electrolysis, a $2 \mu \mathrm{L}$ aliquot of the electrolyte solution was injected into a second Haysep D column (post-electrolysis alcohol detection). Other liquid products (e.g. formate) were analyzed by means of ion exchange chromatography (IC, Metrohm Advanced Modular Ion Chromatograph: L-7100 pump, Metrosep A Supp 7-250 column, conductivity detector).

\section{Results and Discussion}

\subsection{Activation of Cu Foam Electrocatalysts ${ }^{[19]}$}

Fig. 5 displays a prime example of $\mathrm{Cu}$ foams fabricated by means of the DHBT-assisted electrodeposition method. ${ }^{[11]}$ The basic concept of this approach was adapted from the work by Shin et al. ${ }^{[15,16]}$ As the $\mathrm{Cu}$ electrodeposition takes place under rather harsh hydrogen evolution reaction (HER) conditions (e.g. at current densities of $j=-3 \mathrm{~A} \times \mathrm{cm}^{-2}$, see Fig. 4), gas bubbles rapidly evolve on the support electrode and serve as geometric template for the actual metal plating process which is superimposed on the HER. $\mathrm{Cu}$ is deposited only in the bubble-free areas of the support and the emerging porous film. The process of hydrogen bubble
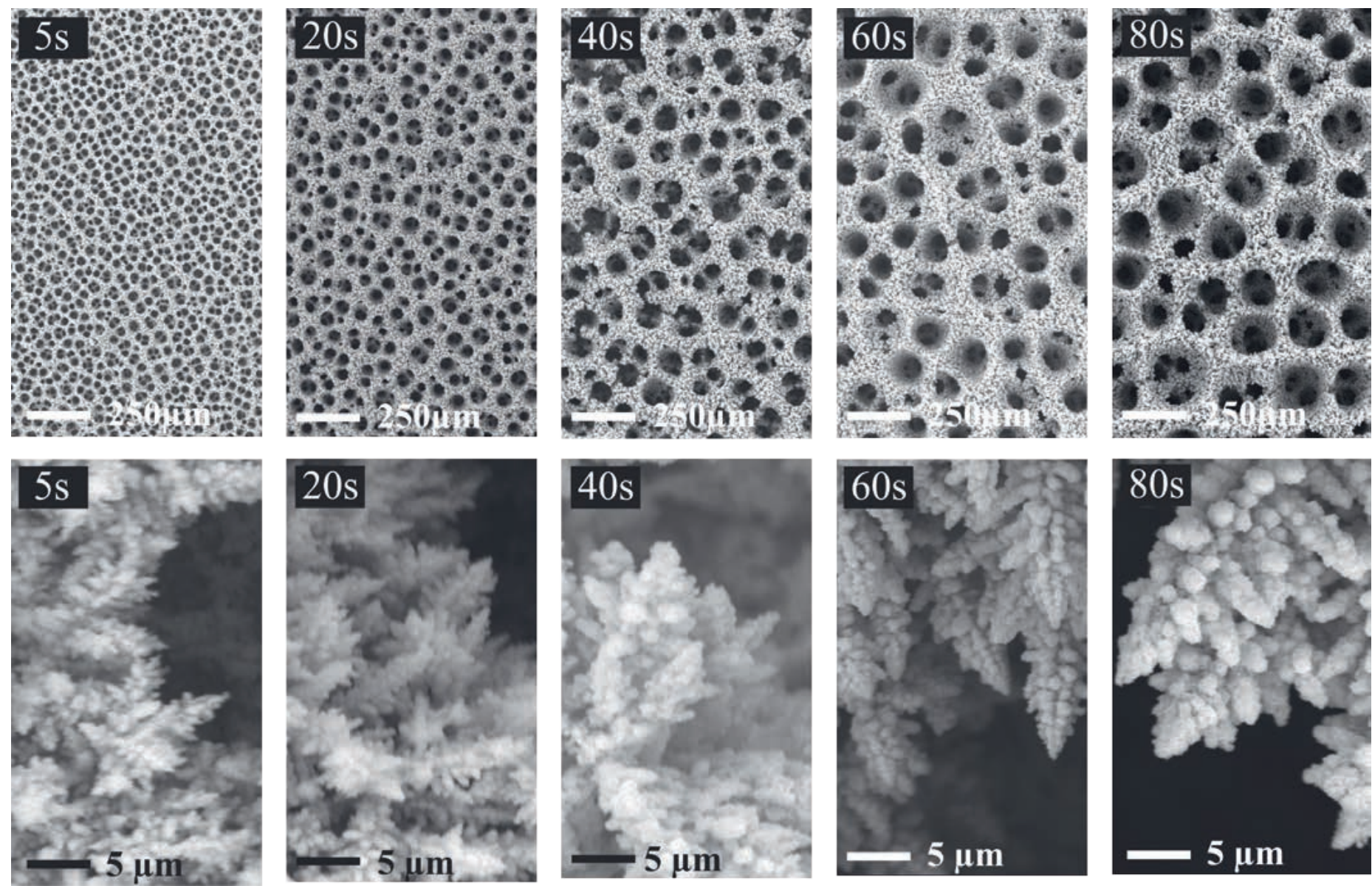

Fig. 5. Top-down SEM analysis showing the surface pore size (upper row) and dendrite size (lower row) evolution as function of the deposition time (exemplified for a Cu foam catalyst). Adapted from ref. [11], with permission of the American Chemical Society. 
nucleation, growth and coalescence is continuous. This is why the average surface pore size increases as function of the deposition time and film thickness (Fig. 5). ${ }^{[11]} \mathrm{A}$ characteristic feature of the formed metal foams is a gradient in the pore sizes along the surface normal. Smallest pores are typically created close to the support electrode whereas the biggest ones are found at the outermost surface of the foam material which is exposed to the (liquid) electrolyte during the $\mathrm{CO}_{2}$ electrolysis reaction. ${ }^{[11]}$

In addition to this primary macro-porosity ( $\mu \mathrm{m}$ length scale), originated by the gaseous $\mathrm{H}_{2}$-template during the metal deposition, the scaffold of the formed $3 \mathrm{D}$ foam itself is porous, too. ${ }^{[11,20,49]}$ The macro-pore sidewalls are composed of randomly distributed $\mathrm{Cu}$ dendrites thus introducing a secondary porosity to the catalyst (nm length scale). ${ }^{[15]}$ Such a dendritic growth mode originates from the applied experimental conditions that impose a deposition rate limited by mass transport of the metal ions and a reduced mobility of the deposited atoms on the emerging foam surface. ${ }^{[11]}$

In particular when alcohols are targeted as products, the electrodeposited catalysts often require further activation prior to the ec-CO $\mathrm{CO}_{2} \mathrm{RR}$, e.g. by thermal annealing in air.[28,50] Fig. 6 displays representative SEM micrographs of an 'as-deposited' $\mathrm{Cu}$ foam and its morphological evolution induced by thermal annealing at $300^{\circ} \mathrm{C}$ for $12 \mathrm{~h}$ in air, and a subsequent $1 \mathrm{~h} \mathrm{CO}$ electrolysis in $\mathrm{CO}_{2}$ sat. $0.5 \mathrm{M}$ bicarbonate solution carried out at $-0.67 \mathrm{~V}$ vs. RHE. Obviously, the macro-porous morphology of the $\mathrm{Cu}$ foam remains completely unaffected by both the thermal annealing in air $(\mathrm{Cu}$ oxidation) and the subsequent ec- $\mathrm{CO}_{2} \mathrm{RR}$, the latter involving the electro-reduction of the formed oxides. ${ }^{[19,20]}$ However, the $\mathrm{Cu}$ foam undergoes substantial morphological alterations on the nm length scale particularly induced by the thermal treatment (see Fig. 6e-h). Following the $12 \mathrm{~h}$ annealing step at $300{ }^{\circ} \mathrm{C}$, the surface of the pristine metallic $\mathrm{Cu}$ foam is completely transformed into a composite material consisting of cuprous $\left(\mathrm{Cu}_{2} \mathrm{O}\right)$ and cupric $(\mathrm{CuO})$ oxides ${ }^{[19,20,28]}$ (denoted $\mathrm{Cu}_{\mathrm{x}} \mathrm{O}$ ). This transformation requires substantial mass transport of oxygen and $\mathrm{Cu}$ species. A combination of ex situ (post-deposition, post-electrolysis) XRD and XPS analysis confirms the composite nature of the oxidic foam. ${ }^{[19,20]}$ It should be noted that the applied annealing temperature of $300{ }^{\circ} \mathrm{C}$ is sufficient to form a crystalline $\mathrm{Cu}_{2} \mathrm{O}$ phase whereas the cupric $\mathrm{CuO}$ remains largely in an amorphous state lacking any long range transitional order. ${ }^{[19,20]}$ Consequently, $\mathrm{Cu}$ (II) species are detected in the XPS but not in the corresponding XRD analysis. ${ }^{[19,20]}$ It should be noted here that, in full agreement with previous studies, the thermal annealing activates the $\mathrm{Cu}$ catalyst for $\mathrm{C} 2$ and $\mathrm{C} 3$ alcohol production. ${ }^{[19]}$ For instance, the partial current density for ethanol formation increases from $j_{\mathrm{EtOH}}=-0.86 \mathrm{~mA} \times \mathrm{cm}^{-2}\left(F E_{\mathrm{EtOH}}=5 \%\right)$ at $-0.77 \mathrm{~V}$ vs. RHE to $j_{\mathrm{EtOH}}=-1.61 \mathrm{~mA} \times \mathrm{cm}^{-2}\left(F E_{\mathrm{EtOH}}=6.7 \%\right)$ at $-0.87 \mathrm{~V}$ vs. RHE. Similarly, the partial current density for n-propanol formation reaches a value of $j_{\mathrm{PrOH}}=-1.72 \mathrm{~mA} \times \mathrm{cm}^{-2}\left(F E_{\mathrm{PrOH}}\right.$ $=7.1 \%$ ) at $-0.87 \mathrm{~V} \cdot{ }^{[19]} \mathrm{A}$ full description of the electrocatalytic performance of the annealed $\mathrm{Cu}$ foam can be found in ref. [19].

More sophisticated operando analytical techniques are required to ultimately address how important oxide species are in particular for the alcohol electrosynthesis via the ec- $\mathrm{CO}_{2} \mathrm{RR}$ on these $\mathrm{Cu}$ foams. Fig. 7 provides an overview on the results of the highly complementary XAS, XRD, and Raman spectroscopic investigations discussed by Dutta et al. ${ }^{[19]}$ Changes in the potential-dependent $\mathrm{Cu} \mathrm{K}$-edge XANES spectra of the $\mathrm{Cu}_{\mathrm{x}} \mathrm{O}$ foam could be attributed to potential-dependent redox state changes of $\mathrm{Cu}$ species (Fig. 7, panel a; selected data set). Panel b in Fig.7 shows the result of a linear combination fitting (LCF) that was applied to the obtained XANES data using $\mathrm{Cu}$ K-edge XANES spectra of a $\mathrm{Cu}$ foil, $\mathrm{Cu}_{2} \mathrm{O}$ and $\mathrm{CuO}$ as reference materials. The plot displays the relative concentrations of the $\mathrm{Cu}(0), \mathrm{Cu}(\mathrm{I})$, and $\mathrm{Cu}$ (II) species present in the $\mathrm{Cu} \mathrm{O}$ foam as a function of the potential applied.[19] The LCF analysis suggests that the $\mathrm{Cu}_{\mathrm{x}} \mathrm{O}$ foam at $+0.6 \mathrm{~V}$ vs. RHE predominantly consists of $\mathrm{CuO}$, whereas only a lower $\mathrm{Cu}_{2} \mathrm{O}$ content was observed (25-35 wt.\%). Upon potential excursion from +0.6 down to $0 \mathrm{~V}$ vs. RHE, the relative abundances of $\mathrm{Cu}(\mathrm{II})$ and $\mathrm{Cu}(\mathrm{I})$ anti-correlate and further negative polarization leads to the onset of oxide reduction to metallic $\mathrm{Cu}(0)$. At potentials below $0 \mathrm{~V}$ vs. RHE the $\mathrm{Cu}(\mathrm{II})$ abundance
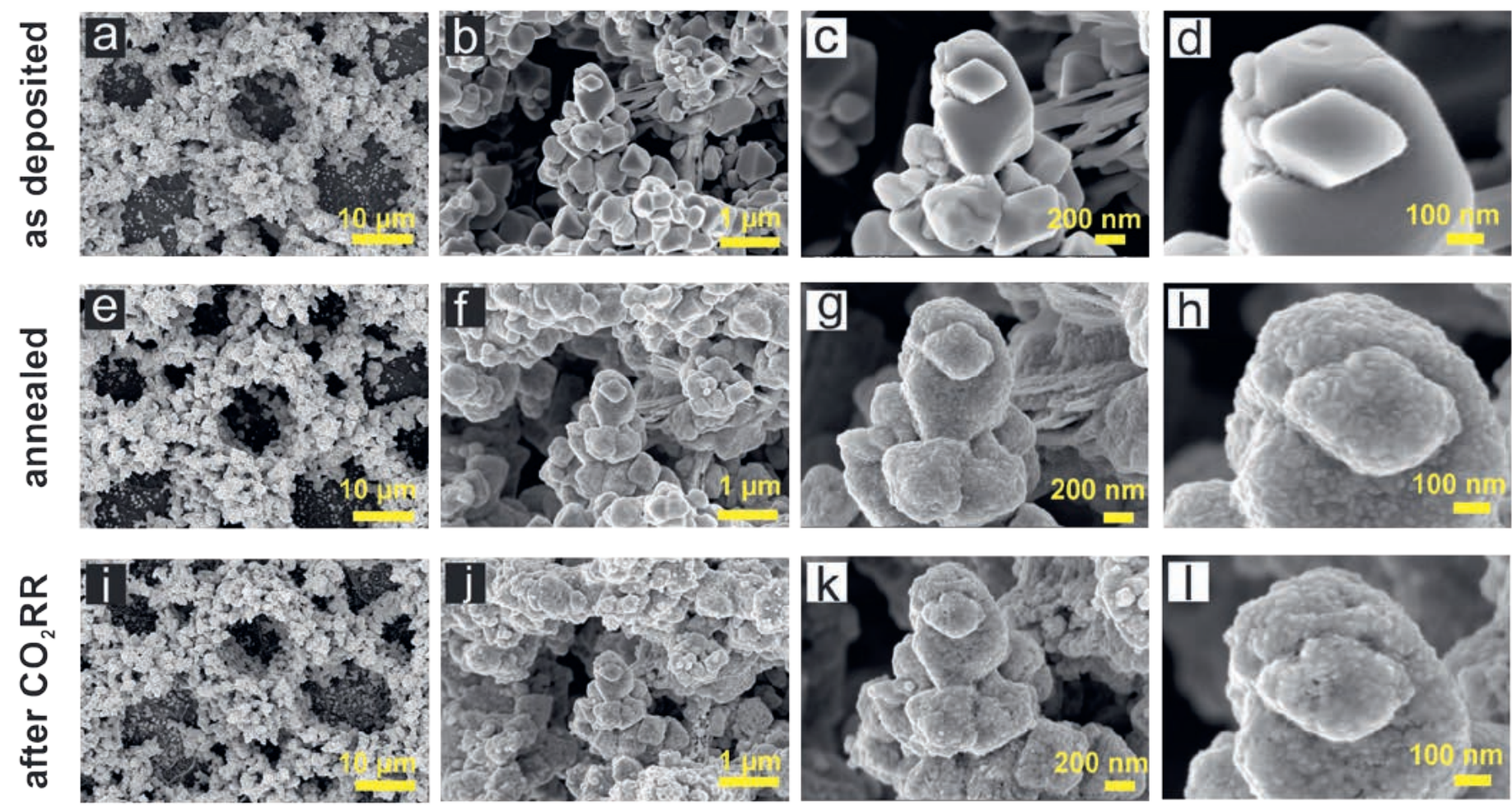

Fig. 6. Identical location (IL) SEM inspection of the Cu foam catalyst. (a-d) As-deposited Cu foam (5 s deposition at $\left.-3 \mathrm{~A} \times \mathrm{cm}^{-2}\right)$; (e-h) Thermally an-

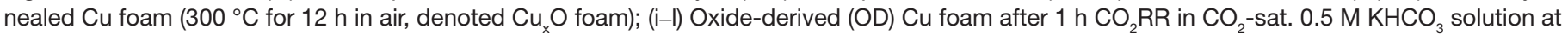
$-0.67 \mathrm{~V}$ vs. RHE. Adapted from ref. [19], with permission of Elsevier. 

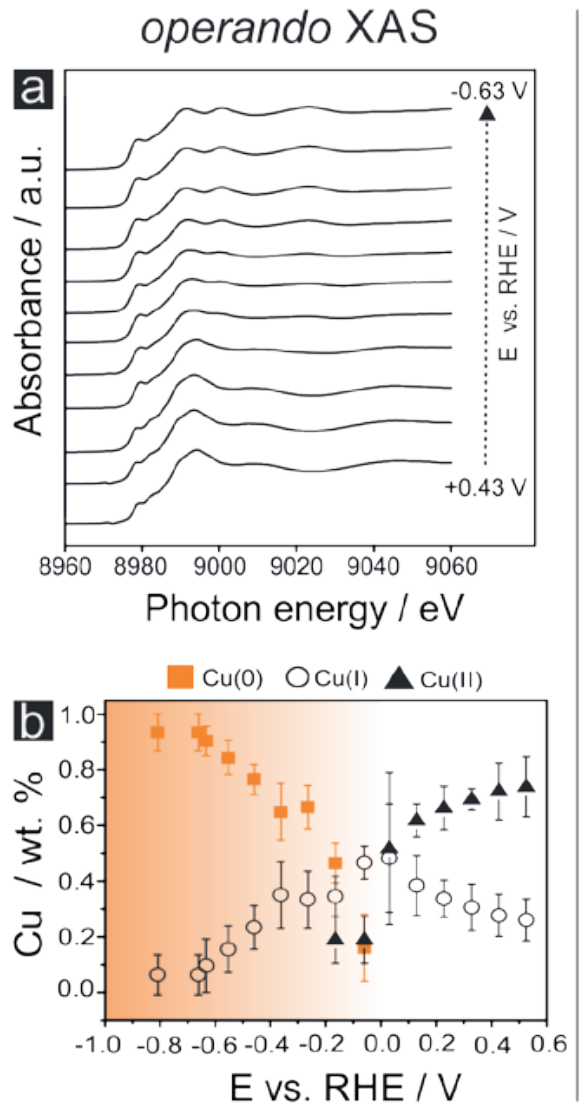
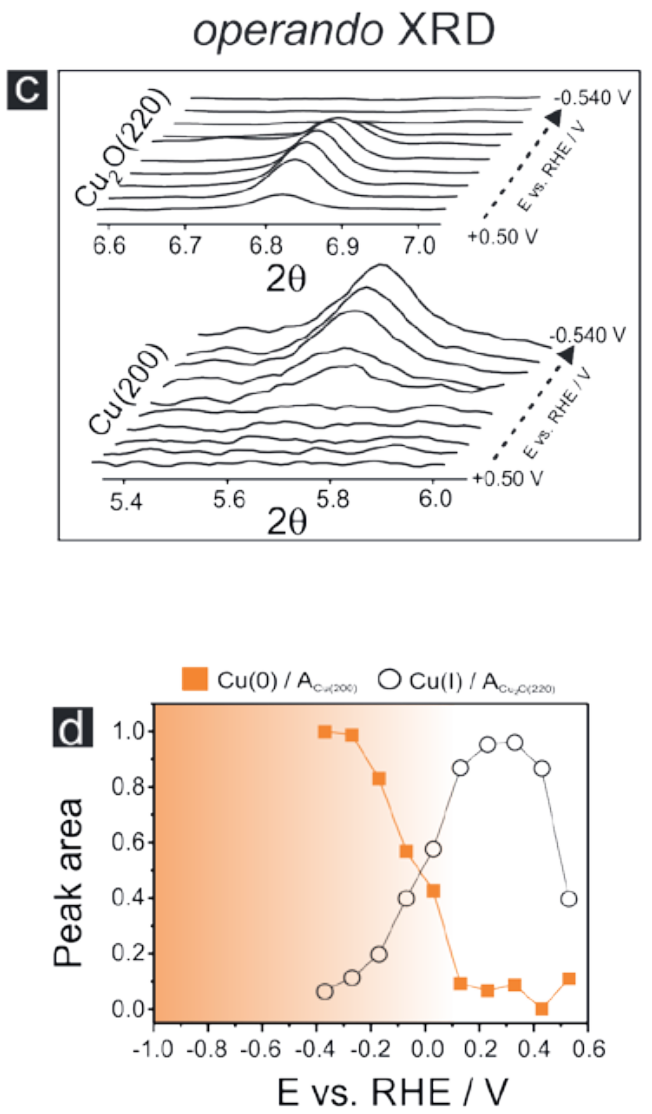

operando Raman

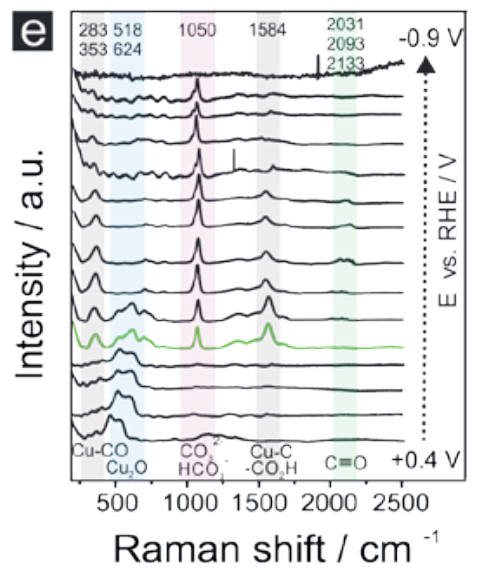

$\mathrm{OCu}(\mathrm{I}) / \mathrm{A}_{\mathrm{aub}}$

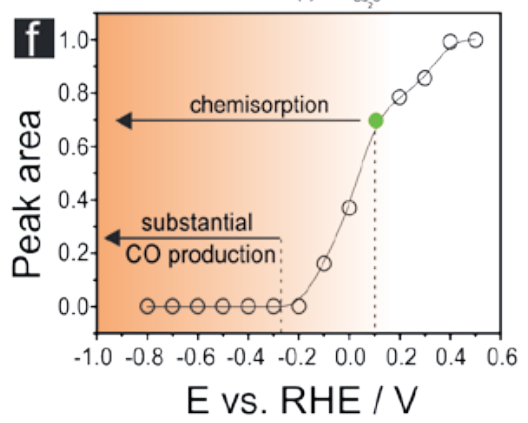

Fig. 7. Survey of experimental operando results demonstrating the potential-dependent oxide-metal transition of the oxidic catalyst precursor (Cu $\mathrm{O}$ foam). (a) Potential-dependent operando XANES spectra ( $\mathrm{Cu}$ K-edge) of the thermally annealed $\mathrm{Cu}_{\text {foam }}\left(\mathrm{Cu}_{\mathrm{x}} \mathrm{O}\right)$ in $\mathrm{CO}_{2}$-sat. $0.5 \mathrm{M} \mathrm{KHCO}_{3}$ solution; (b) Potential-dependent composition of the $\mathrm{Cu}_{\mathrm{x}} \mathrm{O}$ foam (relative content of $\mathrm{Cu}$ species: $\mathrm{Cu}(\mathrm{O}), \mathrm{Cu}(\mathrm{I})$, and $\mathrm{Cu}(\mathrm{II}) \mathrm{derived}$ from a linear combination fitting (LCF) of the XANES spectra shown in (a)); (c) Potential-dependent operando grazing-incidence X-ray diffractograms of the Cu $\mathrm{O}_{2}(220)$ and $\mathrm{Cu}(200)$ reflections; (d) Integrated and normalized peak intensities of the diffractograms shown in (c); (e) Corresponding potential-dependent operando Raman spectra; (f) Integrated and normalized peak intensities of the $\mathrm{Cu}_{2} \mathrm{O}$-related Raman peaks $\left(518 \mathrm{~cm}^{-1}\right.$ and $\left.624 \mathrm{~cm}^{-1}\right)$ shown in (e). The peak areas were normalized with respect to the most intense peaks at most positive electrode potentials. The grey and orange areas in panel $b$, $d$, and $f$ indicate the stability windows of the oxidic and metallic state of Cu, respectively. Adapted from ref. [19], with permission of Elsevier.

drops down to zero, whereas $\mathrm{Cu}(\mathrm{I})$ species are present in the bulk material down to potentials of $-0.5 \mathrm{~V}$ vs. RHE. ${ }^{[19]}$ The potentialdependent decrease of the $\mathrm{Cu}(\mathrm{I})$ content below $0 \mathrm{~V}$ vs. RHE is clearly anti-correlated to the increase of the $\mathrm{Cu}(0)$ abundance. The transition from the oxidic precursor to metallic $\mathrm{Cu}$ in the bulk is completed at about $-0.7 \mathrm{~V}$ vs. RHE. [19]

Operando XRD experiments basically confirm the XAS investigations (panel $\mathrm{c}$ and $\mathrm{d}$ in Fig. 7). As hypothesized on the basis of the XAS results the integrated intensity of the $\mathrm{Cu}_{2} \mathrm{O}(220)$ diffraction peak first increases when sweeping the cathode potential from $+0.5 \mathrm{~V}$ to $+0.2 \mathrm{~V}$ vs. RHE. This trend is consistent with the assumption of an intermediate crystalline $\mathrm{Cu}_{2} \mathrm{O}$ phase which accumulates in the initial stage of the oxide-metal transition in the foam material at the expense of the amorphous $\mathrm{CuO}$ phase. ${ }^{[19]}$ Interestingly, the disappearance of the $\mathrm{Cu}_{2} \mathrm{O}$ related diffraction pattern with negative going potentials is already completed at $-0.4 \mathrm{~V}$ vs. RHE, whereas the XAS experiment indicates the presence of $\mathrm{Cu}(\mathrm{I})$ species for potentials down to $-0.8 \mathrm{~V}$ vs. RHE. These deviations in the particular potential-dependence of the $\mathrm{Cu}(\mathrm{I})(\mathrm{XAS}) / \mathrm{Cu}_{2} \mathrm{O}(\mathrm{XRD})$ stability regime are related to the intrinsic characteristics of both operando techniques. The ultimate reduction of the $\mathrm{Cu}(\mathrm{I})$ to $\mathrm{Cu}(0)$ proceeds most likely via an intermediate amorphous $\mathrm{Cu}(\mathrm{I})$ phase. ${ }^{[19]}$

Among the operando techniques applied Raman spectroscopy is the most surface sensitive one. ${ }^{[19]}$ Raman features observed at $148 \mathrm{~cm}^{-1}, 518 \mathrm{~cm}^{-1}$, and $624 \mathrm{~cm}^{-1}$ can be ascribed to cuprous oxide species $\left(\mathrm{Cu}_{2} \mathrm{O}\right)$, whereas vibrational modes at
$298 \mathrm{~cm}^{-1}$ and $346 \mathrm{~cm}^{-1}$ originate from cupric oxides (panel e and f in Fig. 7 ). ${ }^{[19]}$ Interesting to note is that after exposure to the $0.5 \mathrm{M} \mathrm{KHCO}_{3}$ electrolyte at the open circuit potential, the $\mathrm{CuO}$ related vibrational modes have completely disappeared from the Raman spectra. ${ }^{[19]}$ Only vibrational modes of the cuprous oxide $\left(\mathrm{Cu}_{2} \mathrm{O}\right)$ are left which indicates that the initial catalyst surface is terminated exclusively by $\mathrm{Cu}(\mathrm{I})$ species when exposed to the electrolyte. Both XRD and XAS typically do not show these effects when the oxidic foam is exposed to the electrolyte at OCP.[19] This is due to the dominance of 'bulk' contributions to the data with only minor contributions from the foam surface. Integrated intensities of the $\mathrm{Cu}_{2} \mathrm{O}$ specific Raman features (panel f) follow qualitatively the same trend as observed in the XAS and XRD. However, the 'surface oxide reduction' proceeds apparently faster than the corresponding transition of the oxidic 'bulk phases' probed by operando XAS and XRD and is therefore completed at less negative applied potentials. ${ }^{[19]}$

Operando Raman spectroscopy provides additional information on intermediate species associated to the ec- $\mathrm{CO}_{2} \mathrm{RR}$. Raman modes observed at $283 \mathrm{~cm}^{-1} / 253 \mathrm{~cm}^{-1}, 1050 \mathrm{~cm}^{-1}, 1584 \mathrm{~cm}^{-1}$ and $2031 \mathrm{~cm}^{-1} / 2093 \mathrm{~cm}^{-1} / 2133 \mathrm{~cm}^{-1}$ are attributed to adsorbed CO, $\mathrm{HCO}_{3}^{-}$, and $\mathrm{HCOOH}$ respectively. These intermediates appear only after partial reduction of the oxide to the metallic $\mathrm{Cu}^{\left[{ }^{[19]}\right.}$

The 'holistic view' on the potential-dependent oxide-metal transition using different complementary operando techniques let us safely conclude that the surface and bulk $\mathrm{Cu}$ oxide reduction is completed at potentials more positive than the onset of hydrocar- 


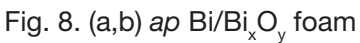
deposited on a carbon cloth support (denoted $\mathrm{Bi} / \mathrm{Bi}_{x} \mathrm{O}_{y} @ \mathrm{GDE}$ ); (c) $\mathrm{CO}_{2} \mathrm{RR}$ product distribution represented as $F E_{\text {formate }}$ vs. E plot (FE: Faradaic efficiency). The annealed foam (denoted $\mathrm{Bi}_{2} \mathrm{O}_{3} @$ GDE) was used as the catalyst; (d) Corresponding $\mathrm{CO}_{2} \mathrm{RR}$ reaction rate represented as $\mathrm{PCD}_{\text {formate }}$ vs. E plot (PCD: partial current density). Note that the only side-product of the $\mathrm{CO}_{2} \mathrm{RR}$ is hydrogen; (e-h) Operando Raman spectroscopy results showing the potential-dependent oxide/sub-carbonate reduction Raman bands at $313 \mathrm{~cm}^{-1}$ and $162 \mathrm{~cm}^{-1}$ were used to probe the presence of oxide and subcarbonate species, respectively; (i) Operando optical inspection of the time-dependent oxide/ sub-carbonate/metal transition in $\mathrm{CO}_{2}$-sat. $0.5 \mathrm{M} \mathrm{KHCO}_{3}$ solution at -0.6 V vs. RHE; (j,k) Proposed reaction mechanisms of formate formation. Adapted from ref. [18] with permission of the American Chemical Society.
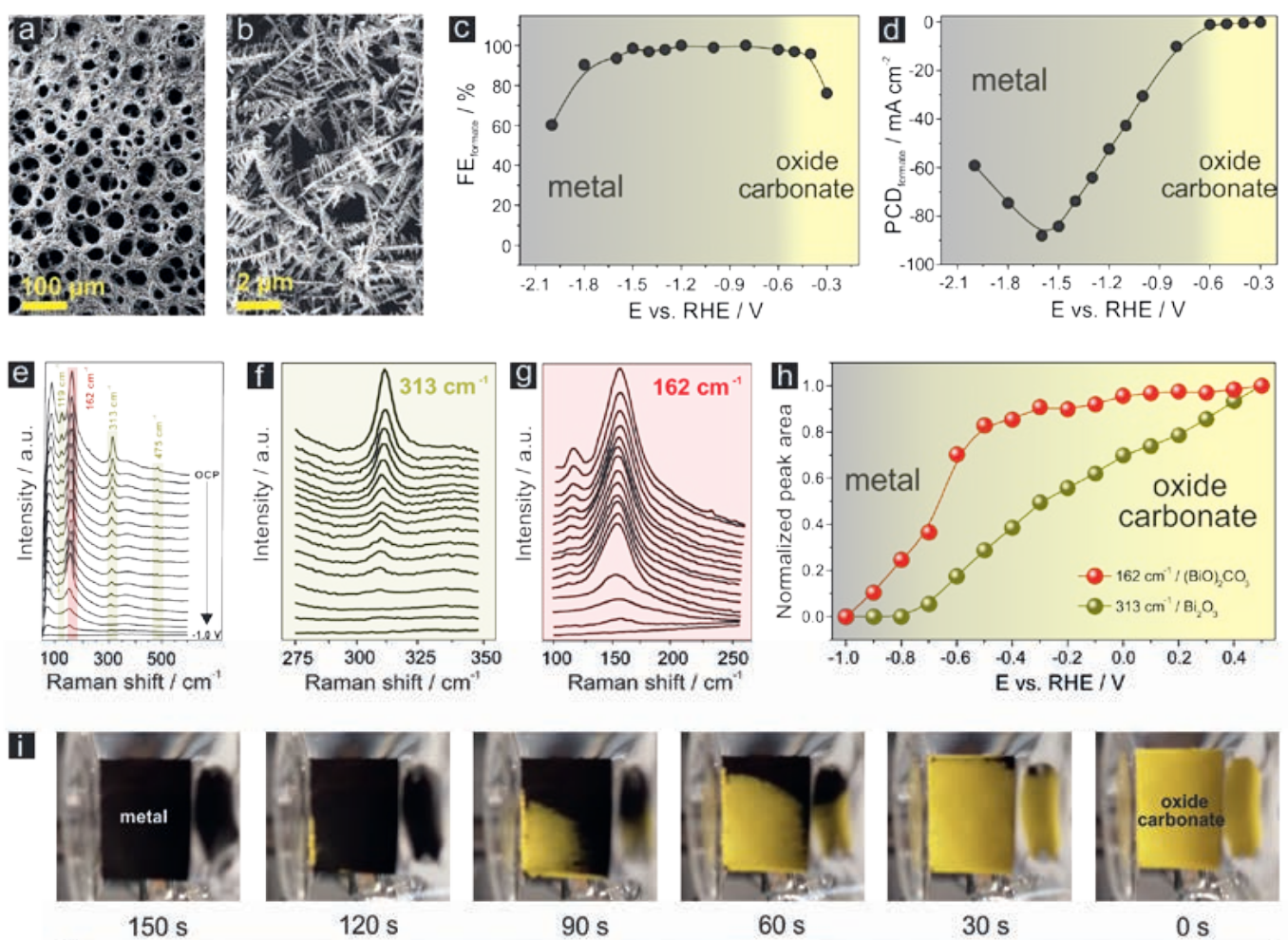

$60 \mathrm{~s}$

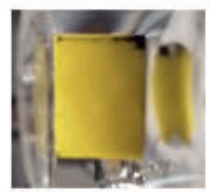

$30 \mathrm{~s}$

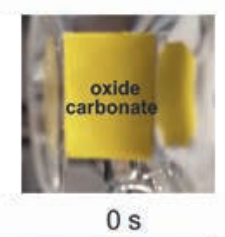

Elapsed time at $E=-0.6 \mathrm{~V}$ vs. RHE
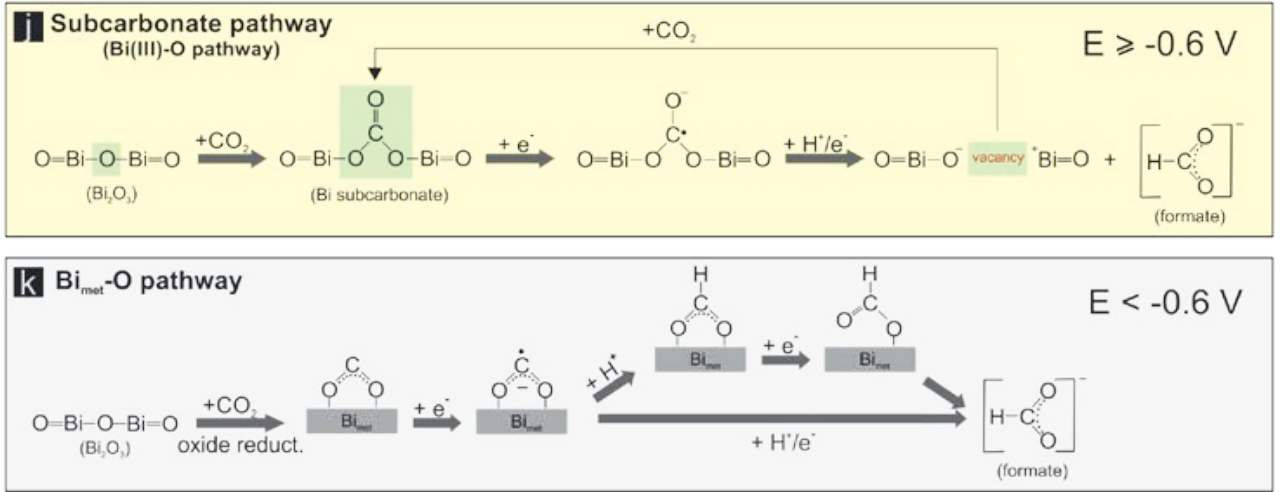

bon and alcohol formation. Obviously, oxidic species do not play any significant role for the ec- $\mathrm{CO}_{2} \mathrm{RR}$ on $\mathrm{Cu}$ in general and for the alcohol production in particular.

\subsection{Activation of $\mathrm{Bi} \mathrm{Bi}_{2} \mathrm{O}_{3}$ Foam Electrocatalysts ${ }^{[18]}$}

A novel bismuth oxide $\left(\mathrm{Bi}_{2} \mathrm{O}_{3}\right)$ foam-type of catalyst (precursor) material has been produced by means of an additive-assisted DHBT electrodeposition followed by thermal annealing at $300^{\circ} \mathrm{C}$ for 12 h. ${ }^{[18]}$ This DHBT approach could successfully be applied to functionalize technical supports, e.g. gas diffusion electrodes (GDEs). This transfer of the foam catalyst from planar substrates (e.g. $\mathrm{Cu}$ foils $\left.{ }^{[11]}\right)$ to highly porous carbon supports is considered a crucial technical pre-requisite for any future application of this novel catalyst concept in gas-fed $\left(\mathrm{CO}_{2}\right)$ electrolyzer systems. The latter will be vital to achieve ec- $\mathrm{CO}_{2} \mathrm{RR}$ current densities which are of technological relevance $\left(j_{\mathrm{CO} 2 \mathrm{RR}}>200 \mathrm{~mA} \times \mathrm{cm}^{-2}\right)$. It should be noted that the resulting (surface) pore sizes are altered when changing the support material. ${ }^{[18]}$ In general, the pore size distribution is substantially broader when the foam materials are electrodeposited on porous carbon supports compared to respective metal foaming processes on planar metal foil supports. Fig. 8a,b shows representative top-down SEM images of the as-prepared $\mathrm{Bi}$ foam on the technical carbon support denoted hereafter $a p \mathrm{Bi} /$
$\mathrm{Bi}_{2} \mathrm{O}_{3} @$ GDE. Note that the as-prepared oxophilic Bi foam is typically covered by an ultrathin $\mathrm{Bi}_{2} \mathrm{O}_{3}$ layer after its emersion from the Bi plating bath. ${ }^{[18]}$

The thermal treatment at $300{ }^{\circ} \mathrm{C}$ for $12 \mathrm{~h}$ in air leaves the macroporosity of $a p \mathrm{Bi} / \mathrm{Bi}_{2} \mathrm{O}_{3}$ foam fully unaffected (see also Fig. 9), similar to the $\mathrm{Cu}$ case (Fig. 6). This annealing yields a fully oxidized $\mathrm{Bi}_{2} \mathrm{O}_{3}$ foam which shows a characteristic yellow color (Fig. $8 \mathrm{i}$ at $0 \mathrm{~s}$ ).

The formed oxidic Bi foam exhibits a superior electrocatalytic selectivity toward formate production with Faradaic efficiencies (FEs) never falling below $90 \%$ within an extraordinarily huge potential window of $\sim 1100 \mathrm{mV}$ (max. $F E_{\text {formate }}=$ $100 \%$ at -0.8 V vs. RHE). ${ }^{[18]}$ Panel c and d of Fig. 8 depict the potential-dependent Faradaic efficiencies (c) and partial current densities (d) of formate production when the electrolysis is carried out from aqueous $\mathrm{CO}_{2}$-sat. $0.5 \mathrm{M} \mathrm{KHCO}_{3}$ solution.

For the first time, operando Raman spectroscopy provided clear experimental evidence for the embedment of $\mathrm{CO}_{2}$ into an oxidic matrix (so-called 'sub-carbonate' formation) at low overpotentials prior to and during the $\mathrm{CO}_{2}$ reduction reaction (Fig. 8e-h). We used the Raman bands at $313 \mathrm{~cm}^{-1}$ and $162 \mathrm{~cm}^{-1}$ as characteristic 'fingerprints' for the presence of $\mathrm{Bi}$ oxide and $\mathrm{Bi}$ subcarbonate species, respectively. ${ }^{[18]}$ Note that 


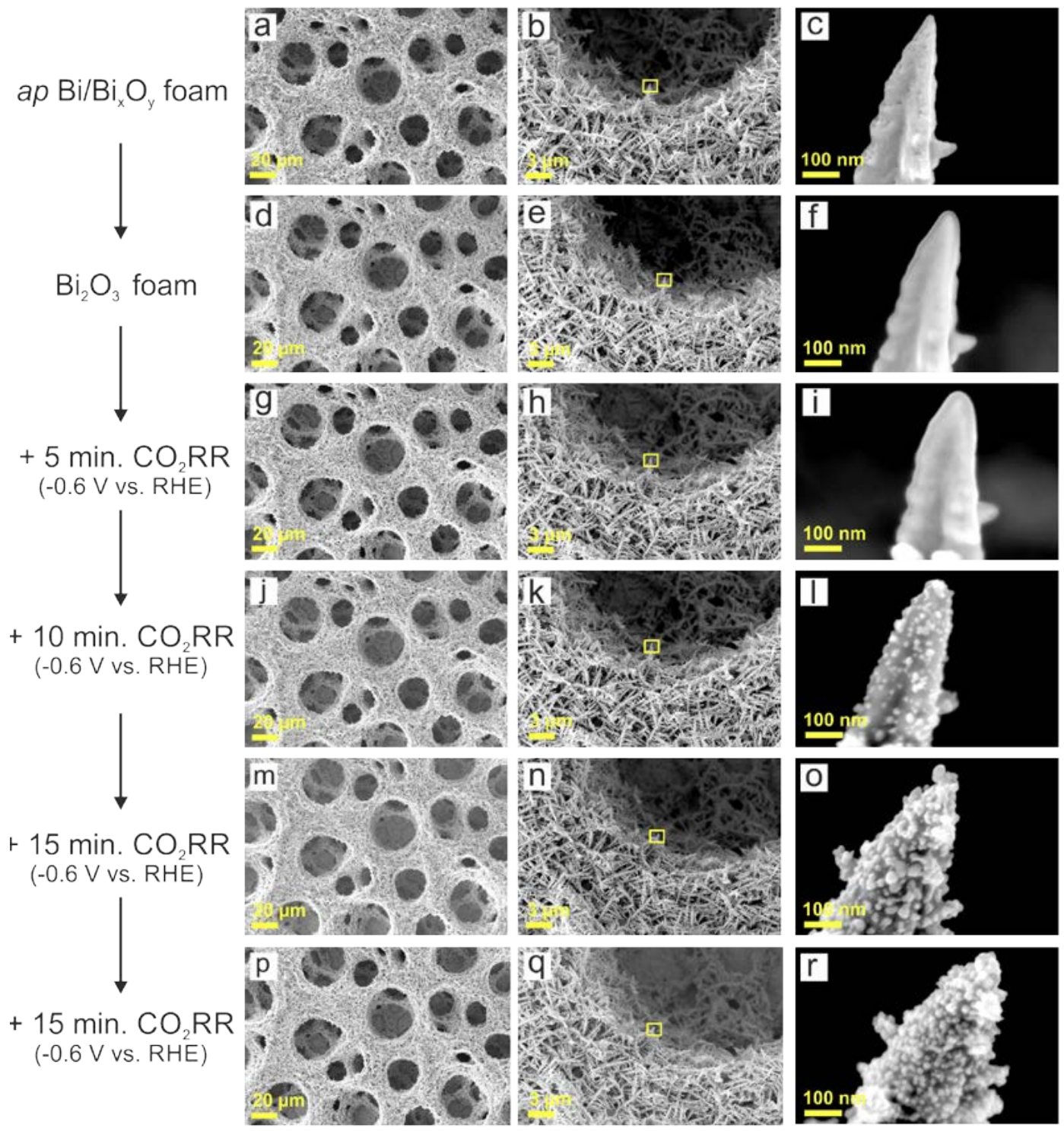

Fig. 9. (a-r) Identical location (IL) SEM inspection of morphological changes associated to the thermal annealing of the ap $\mathrm{Bi} / \mathrm{Bi}_{x} \mathrm{O}_{y}$ foam, the sub-carbonate formation and subsequent potentiostatic $\mathrm{CO}_{2}$ electrolysis in $\mathrm{CO}_{2}$-sat. $0.5 \mathrm{M} \mathrm{KHCO}_{3}$ solution at $-0.6 \mathrm{~V}$ vs. RHE. Adapted from ref. [18] with permission of the American Chemical Society.

the exchange of the oxide by the sub-carbonate is a spontaneous and rather fast process which takes place in the $\mathrm{CO}_{2}$-sat. 0.5 $\mathrm{M} \mathrm{KHCO}_{3}$ solution even at the open circuit potential without initiating the ec- $\mathrm{CO}_{2} \mathrm{RR}$. Indeed, the potential-dependent integrated intensities of the Raman bands at $313 \mathrm{~cm}^{-1}$ and $162 \mathrm{~cm}^{-1}$ suggest that formed sub-carbonate species are more stable than the corresponding oxides (Fig. 8h). As shown in Fig. 8i, this transition from the oxide/sub-carbonate to the metallic Bi state is accompanied by a characteristic color change from yellow (oxide) to black (metal).

These excellent electrocatalytic characteristics of the novel Bi foam catalysts result from the coupling of two distinct reaction pathways of formate formation which are active (i) in the presence of the (partly-reduced) $\mathrm{Bi}_{2} \mathrm{O}_{3}$ foam at low overpotentials (sub-carbonate pathway) and (ii) on the corresponding metallic Bi foam catalyst at medium and high overpotentials (Bi-O pathway). The reaction mechanisms, proposed also on the basis of the operando Raman results, are displayed in Fig. $8 \mathrm{j}, \mathrm{k}$. To probe in more detail the structural and morphological changes which take place on the nanometer length scale upon sub-carbonate formation and partial electro-reduction of the oxidic precursor during ec-CO RR we further applied the identical location (IL) scanning electron microscopy (SEM) technique by sequentially imaging the same single spot on the catalyst surface after the initial electrodeposition (as prepared), after the thermal annealing treatment, and after a series of dedicated $\mathrm{CO}_{2}$ electrolyses. The results of this IL-SEM analysis are depicted in Fig. 9 and demonstrate severe morphological changes on the nm length scale which go along with (i) the oxidation upon thermal annealing, (ii) the sub-carbonate formation when exposed to the $\mathrm{CO}_{2}$-sat. bicarbonate solution, and (iii) the ensuing catalyst electro-reduction into the metallic state at higher applied overpotentials.

These microscopic results impressively demonstrate that the actually active catalyst forms only under reactive conditions.

\section{Conclusions}

Herein we have demonstrated the usefulness of advanced operando analytical techniques to probe the (chemical) state evolution of foam-type catalysts under reactive conditions, e.g. in the course of $\mathrm{CO}_{2}$ electrolysis. In particular for the case of $\mathrm{Cu}$ foams and their oxidic precursors it could be shown that a complementary operando analysis approach is mandatory to derive a full understanding of the catalyst activation process which involves the potential-driven electro-reduction of the oxidic precursors. Due to intrinsic technical limitations associated with 
each applied operando technique (e.g. XAS, XRD, and Raman spectroscopy) the probed potential dependence of the observed structural and compositional alterations is slightly different in all cases. However, from all applied operando techniques it can be concluded that the oxide-metal transition is completed prior to the onset of hydrocarbon or alcohol formation. The active $\mathrm{Cu}$ catalyst can be indeed considered as metallic (oxide-derived).

The understanding of the catalyst activation process is, however, much more complex in case of $\mathrm{Bi}$ foams and their oxidic counterparts. As evidenced by the comparison of operando Raman spectroscopy results and corresponding electrochemical performance testing, both the oxidic and the metallic foams are active towards ec- $\mathrm{CO}_{2} \mathrm{RR}$ (formate production). The scenario becomes even more complex due to the rapid exchange of oxidic species by sub-carbonates in the presence of (dissolved) $\mathrm{CO}_{2}$ in the electrolyte solution. It is the coupling of two distinct reaction pathways of formate production (sub-carbonate pathway at low overpotentials; Bi-O pathway at high overpotentials) that leads to the extraordinarily broad potential window of $\sim 1100 \mathrm{mV}$ in which the Faradaic efficiency of formate production does not fall below $90 \%$.

\section{Acknowledgments}

M.R. and K.K. acknowledge the financial support by the Swiss Government Excellence Scholarship (ESKAS). S. V. acknowledges support from the National Research, Development and Innovation Office of Hungary (NKFIH grant FK135375). P.B. acknowledges the financial support by the NCCR Catalysis and by the Swiss National Science Foundation (SNSF, Grant code 200020_172507).

Received: July 1, 2021

[1] E. V. Kondratenko, G. Mul, J. Baltrusaitis, G. O. Larrazabal, J. Perez-Ramirez, Energy Environ. Sci. 2013, 6, 3112 , https://doi.org/10.1039/C3EE41272E

[2] M. Fasihi, O. Efimova, C. Breyer, J. Clean. Prod. 2019, 224, 957, https://doi.org/10.1016/j.jclepro.2019.03.086

[3] S. Fujikawa, R. Selyanchyn, T. Kunitake, Polym. J. 2021, 53, 111, https://doi.org/10.1038/s41428-020-00429-Z

[4] N. McQueen, K. V. Gomes, C. McCormick, K. Blumanthal, M. Pisciotta, J. Wilcox, Prog. Energy 2021, 3, 032001, https://doi.org/10.1088/2516-1083/abf1ce

[5] T. Haas, R. Krause, R. Weber, M. Demler, G. Schmid, Nat. Catal. 2018, 1, 32, https://doi.org/10.1038/s41929-017-0005-1

[6] N. Kittner, F. Lill, D. M. Kammen, Nat. Energy 2017, 2, 17125, https://doi.org/10.1038/nenergy.2017.125

[7] B. D. Solomon, K. Krishna, Energy Policy 2011, 39, 7422, https://doi.org/10.1016/j.enpol.2011.09.009

[8] A. V. Rudnev, Y.-C. Fu, I. Gjuroski, F. Stricker, J. Furrer, N. Kovács, S. Vesztergom, P. Broekmann, ChemPhysChem 2017, 18, 3153, https://doi.org/10.1002/cphc.201700737

[9] J. Durst, A. Rudnev, A. Dutta, Y. Fu, J. Herranz, V. Kaliginedi, A. Kuzume, A. A. Permyakova, Y. Paratcha, P. Broekmann, T. J. Schmidt, Chimia 2015 69, 769, https://doi.org/10.2533/chimia.2015.769

[10] Y. Hori, in 'Modern Aspects of Electrochemistry', Springer, New York, 2008, 89, https://doi.org/10.1007/978-0387-49489-0_3.

[11] A. Dutta, M. Rahaman, N. C. Luedi, M. Mohos, P. Broekmann, ACS Catal. 2016, 6, 3804, https://doi.org/10.1021/acscatal.6b00770

[12] J. Quinson, S. Neumann, T. Wannmacher, L. Kacenauskaite, M. Inaba, J. Bucher, F. Bizzotto, S. B. Simonsen, L. T. Kuhn, D. Bujak, A. Zana, M. Arenz, S. Kunz, Angew. Chem. Int. Ed. 2018, 57, 12338, https://doi.org/10.1002/anie.201807450

[13] M. de Jesus Gálvez-Vázquez, P. Moreno-García, H. Xu, Y. Hou, H. Hu, I. Z. Montiel, A. V. Rudnev, S. Alinejad, V. Grozovski, B. J. Wiley, M. Arenz, P. Broekmann, ACS Catal. 2020, 10, 13096, https://doi.org/10.1021/acscatal.0c03609

[14] M. d. J. Gálvez-Vázquez, S. Alinejad, H. Hu, Y. Hou, P. Moreno-García, A. Zana, G. K. H. Wiberg, P. Broekmann, M. Arenz, Chimia 2019, 73, 922, https://doi.org/10.2533/chimia.2019.922

[15] H. C. Shin, M. Liu, Chem. Mater. 2004, 16, 5460, https://doi.org/10.1021/cm048887b

[16] H. C. Shin, J. Dong, M. Liu, Adv. Mater. 2004, 16, 237, https://doi.org/10.1002/adma.200305660
[17] S. Vesztergom, A. Dutta, M. Rahaman, K. Kiran, I. Zelocualtecatl Montiel, P. Broekmann, ChemCatChem 2021, 13, 1039, https://doi.org/10.1002/cctc.202001145

[18] A. Dutta, I. Zelocualtecatl Montiel, K. Kiran, A. Rieder, V. Grozovski, L. Gut, P. Broekmann, ACS Catal. 2021, 11, 4988, https://doi.org/10.1021/acscatal.0c05317

[19] A. Dutta, M. Rahaman, B. Hecker, J. Drnec, K. Kiran, I. Zelocualtecatl Montiel, D. Jochen Weber, A. Zanetti, A. Cedeño López, I. Martens, P. Broekmann, M. Oezaslan, J. Catal. 2020, 389, 592, https://doi.org/10.1016/j.jcat.2020.06.024

[20] A. Dutta, M. Rahaman, M. Mohos, A. Zanetti, P. Broekmann, ACS Catal. 2017, 7, 5431, https://doi.org/10.1021/acscatal.7b01548

[21] M. G. Kibria, C.-T. Dinh, A. Seifitokaldani, P. De Luna, T. Burdyny, R. Quintero-Bermudez, M. B. Ross, O. S. Bushuyev, F. P. García de Arquer, P. Yang, D. Sinton, E. H. Sargent, Adv. Mater. 2018, 30, 1804867 , https://doi.org/10.1002/adma.201804867

[22] Y. Hori, A. Murata, R. Takahashi, J. Chem. Soc., Faraday Trans. 11989 85, 2309, https://doi.org/10.1039/F19898502309

[23] Y. Hori, I. Takahashi, O. Koga, N. Hoshi, J. Phys. Chem. B 2002, 106, 15 , https://doi.org/10.1021/jp013478d

[24] S. Ma, M. Sadakiyo, R. Luo, M. Heima, M. Yamauchi, P. J. A. Kenis, J. Power Sources 2016, 301, 219, https://doi.org/10.1016/j.jpowsour.2015.09.124

[25] J. J. Kim, D. P. Summers, K. W. Frese, J. Electroanal. Chem. 1988, 245 223, https://doi.org/10.1016/0022-0728(88)80071-8

[26] K. P. Kuhl, T. Hatsukade, E. R. Cave, D. N. Abram, J. Kibsgaard, T. F. Jaramillo, J. Am. Chem. Soc. 2014, 136, 14107, https://doi.org/10.1021/ja505791r

[27] M. Rahaman, K. Kiran, I. Z. Montiel, V. Grozovski, A. Dutta, P. Broekmann, Green Chem. 2020, 22, 6497, https://doi.org/10.1039/D0GC01636E

[28] M. Rahaman, A. Dutta, A. Zanetti, P. Broekmann, ACS Catal. 2017, 7, 7946, https://doi.org/10.1021/acscatal.7b02234

[29] R. Kas, R. Kortlever, A. Milbrat, M. T. M. Koper, G. Mul, J. Baltrusaitis, Phys. Chem. Chem. Phys. 2014, 16, 12194 , https://doi.org/10.1039/C4CP01520G

[30] C. W. Li, J. Ciston, M. W. Kanan, Nature 2014, 508, 504, https://doi.org/10.1038/nature13249

[31] K. W. Frese, J. Electrochem. Soc. 1991, 138, 3338, https://doi.org/10.1149/1.2085411

[32] M. Ma, K. Djanashvili, W. A. Smith, Phys. Chem. Chem. Phys. 2015, 17, 20861, https://doi.org/10.1039/C5CP03559G

[33] D. Gao, I. Zegkinoglou, N. J. Divins, F. Scholten, I. Sinev, P. Grosse, B. Roldan Cuenya, ACS Nano 2017, 11, 4825 , https://doi.org/10.1021/acsnano.7b01257

[34] C. W. Li, M. W. Kanan, J. Am. Chem. Soc. 2012, 134, 7231, https://doi.org/10.1021/ja3010978

[35] B. Beverskog, I. Puigdomenech, J. Electrochem. Soc. 1997, 144, 3476, https://doi.org/10.1149/1.1838036

[36] A. Verdaguer-Casadevall, C. W. Li, T. P. Johansson, S. B. Scott, J. T. McKeown, M. Kumar, I. E. L. Stephens, M. W. Kanan, I. Chorkendorff, J. Am. Chem. Soc. 2015, 137, 9808, https://doi.org/10.1021/jacs.5b06227

[37] H. Mistry, A. S. Varela, C. S. Bonifacio, I. Zegkinoglou, I. Sinev, Y. W. Choi, K. Kisslinger, E. A. Stach, J. C. Yang, P. Strasser, B. R. Cuenya, Nat. Commun. 2016, 7, https://doi.org/10.1038/ncomms12123

[38] A. Eilert, F. Cavalca, F. S. Roberts, J. Osterwalder, C. Liu, M. Favaro, E. J. Crumlin, H. Ogasawara, D. Friebel, L. G. M. Pettersson, A. Nilsson, J. Phys. Chem. Lett. 2017, 8, 285, https://doi.org/10.1021/acs. jpclett.6b02273

[39] F. Cavalca, R. Ferragut, S. Aghion, A. Eilert, O. Diaz-Morales, C. Liu, A L. Koh, T. W. Hansen, L. G. M. Pettersson, A. Nilsson, J. Phys. Chem. C 2017, 121, 25003, https://doi.org/10.1021/acs.jpcc.7b08278

[40] M. Fields, X. Hong, J. K. Nørskov, K. Chan, J. Phys. Chem. C 2018, 122, 16209, https://doi.org/10.1021/acs.jpcc.8b04983

[41] A. J. Garza, A. T. Bell, M. Head-Gordon, J. Phys. Chem. Lett. 2018, 9 601, https://doi.org/10.1021/acs.jpclett.7b03180

[42] P. Grosse, D. Gao, F. Scholten, I. Sinev, H. Mistry, B. Roldan Cuenya, Angew. Chem. Int. Ed. 2018, 57, 6192, https://doi.org/10.1002/ anie. 201802083

[43] K. J. J. Mayrhofer, S. J. Ashton, J. C. Meier, G. K. H. Wiberg, M. Hanzlik, M. Arenz, J. Power Sources 2008, 185, 734 , https://doi.org/10.1016/j.jpowsour.2008.08.003

[44] T. Kottakkat, K. Klingan, S. Jiang, Z. P. Jovanov, V. H. Davies, G. A. M. El-Nagar, H. Dau, C. Roth, ACS Appl. Mater. Interfaces 2019, 11, 14734, https://doi.org/10.1021/acsami.8b22071

[45] M. R. Antonio, L. Soderholm, I. Song, J. Appl. Electrochem. 1997, 27, 784, https://doi.org/10.1023/A:1018464526864

[46] I. Martens, R. Chattot, M. Rasola, M. V. Blanco, V. Honkimäki, D. Bizzotto, D. P. Wilkinson, J. Drnec, ACS Appl. Energy Mater. 2019, 2, 7772, https://doi.org/10.1021/acsaem.9b00982

[47] A. Dutta, A. Kuzume, M. Rahaman, S. Vesztergom, P. Broekmann, ACS Catal. 2015, 5, 7498, https://doi.org/10.1021/acscatal.5b02322 
[48] A. Dutta, A. Kuzume, V. Kaliginedi, M. Rahaman, I. Sinev, M. Ahmadi, B. R. Cuenya, S. Vesztergom, P. Broekmann, Nano energy 2018, 53, 828, https://doi.org/10.1016/j.nanoen.2018.09.033

[49] A. Dutta, C. E. Morstein, M. Rahaman, A. Cedeño López, P. Broekmann, ACS Catal. 2018, 8, 8357, https://doi.org/10.1021/acscatal.8b01738

[50] A. Dutta, I. Z. Montiel, R. Erni, K. Kiran, M. Rahaman, J. Drnec, P. Broekmann, Nano Energy 2020, 68, 104331, https://doi.org/10.1016/j.nanoen.2019.104331

\section{License and Terms}

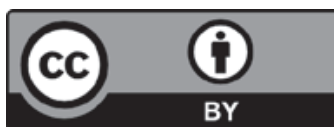

This is an Open Access article under the terms of the Creative Commons Attribution License CC BY 4.0. The material may not be used for commercial purposes.

The license is subject to the CHIMIA terms and conditions: (http:// chimia.ch/component/sppagebuilder/?view=page \&id=12).

The definitive version of this article is the electronic one that can be found at https://doi.org/10.2533/chimia.2021.733 